\title{
Correction to "Integrating Behavioral and Physical Health Care in the Real World: Early Lessons from Advancing Care Together"
}

In the above-mentioned article, ${ }^{1}$ a column in Table 2 has duplicate data (i.e., the commercial insurance $\%$ appears twice in the table, once under \% commercial and once under \% uninsured). The electronic version on the Journal of the American Board of Family Medicine website has been corrected. We apologize for the error, and we regret any confusion or inconvenience it may have caused.

\section{Reference}

1. Davis M, Balasubramanian BA, Waller E, Miller BF, Green LA, Cohen DJ. Integrating behavioral and physical health care in the real world: early lessons from Advancing Care Together. J Am Board Fam Med 2013;26:588602. 